\title{
Two Face-Diagonally Linked Cuboid Coordination Networks with Enhanced Thermal Stability
}

\author{
Ming-Hua You ${ }^{*} *$, Meng-Hua Li ${ }^{*}$, and Mei-Jin Lin $*$ * \\ $\dagger$ College of Materials Science and Engineering, Fujian University of Technology, China, 350118. \\ E-mail: 457443290@qq.com \\ \$ Key Laboratory of Molecule Synthesis and Function Discovery (Fujian Province University), \\ College of Chemistry, Fuzhou University, Fuzhou, 350108, China. E-mail: meijin_lin@fzu.edu.cn.
}

\section{Table of Contents:}

1. NMR data of $\mathbf{T} \mathbf{2}$ S2

2. Additional Figures for Hybrids 1-2 S3 
1. NMR data of $\mathbf{T 2}$

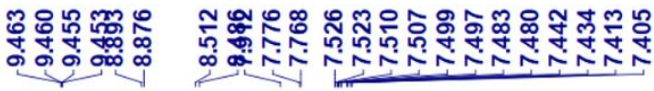

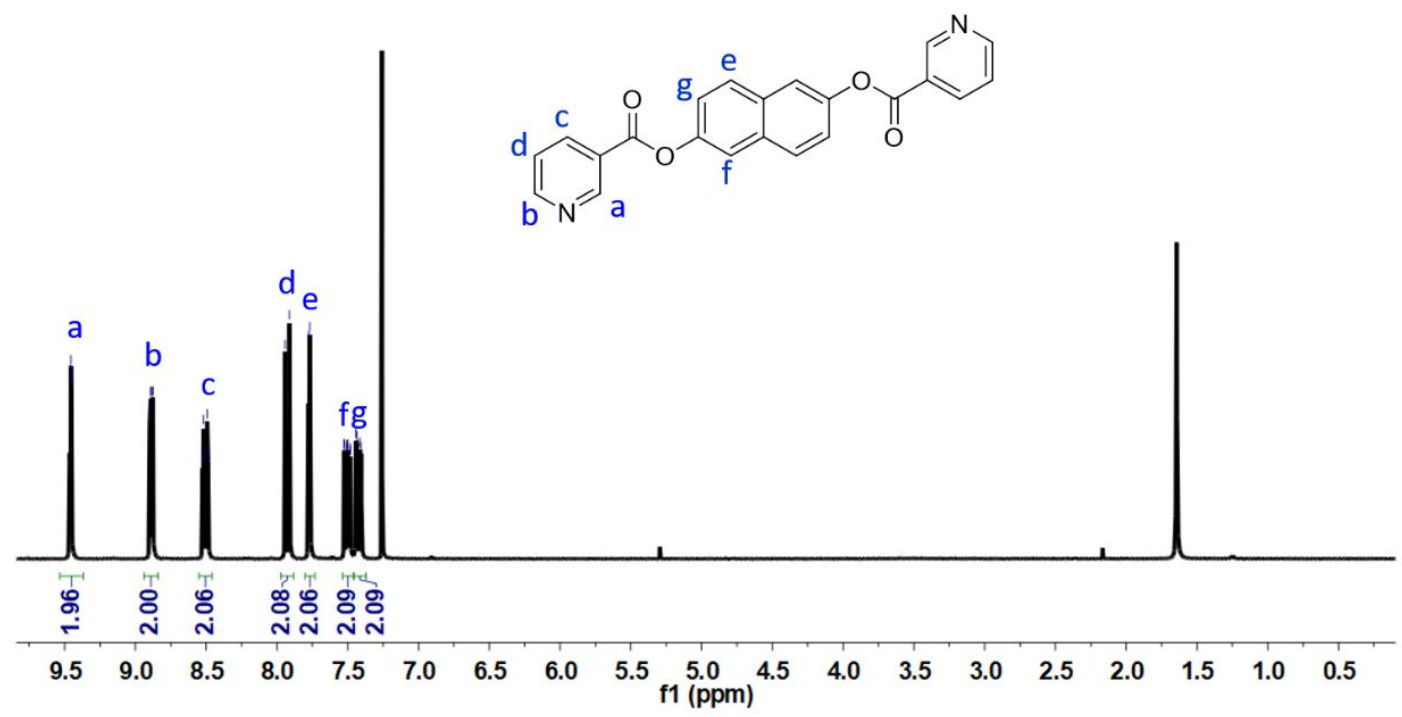

Fig. S1. ${ }^{1} \mathrm{HNMR}$ spectrum of $\mathrm{T} 2\left(300 \mathrm{MHz}, \mathrm{CDCl}_{3}, 298 \mathrm{~K}\right)$

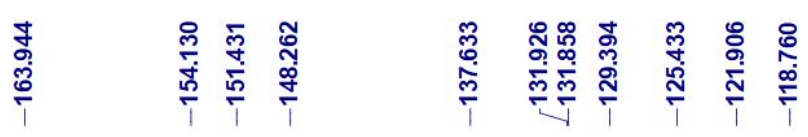

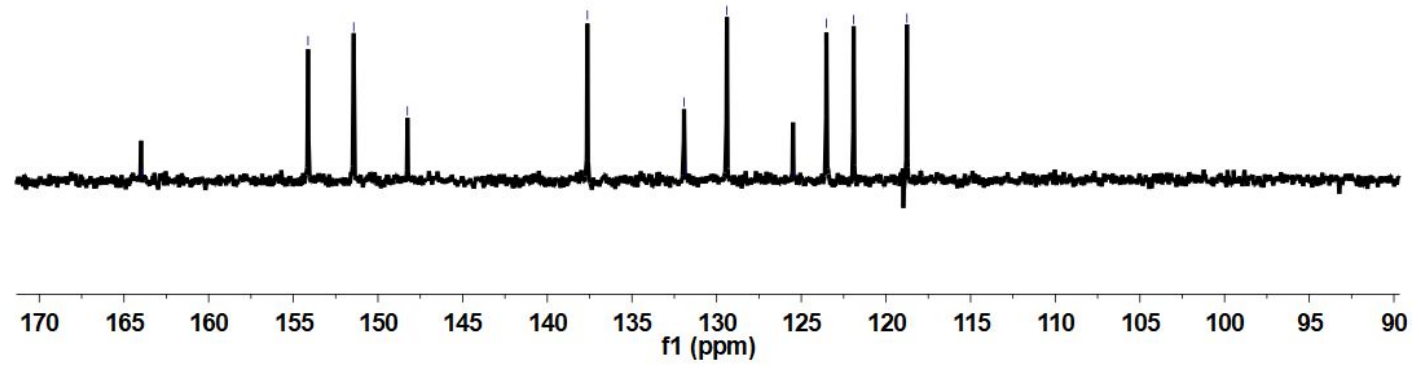

Fig. S2. ${ }^{13} \mathrm{CNMR}$ spectrum of $\mathrm{T} 2\left(75 \mathrm{MHz}, \mathrm{CDCl}_{3}, 298 \mathrm{~K}\right)$ 


\section{Additional Figures for Hybrids 1-2}

(a)

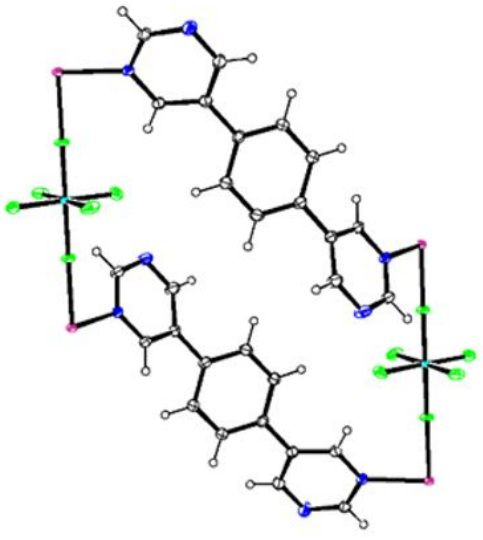

(b)

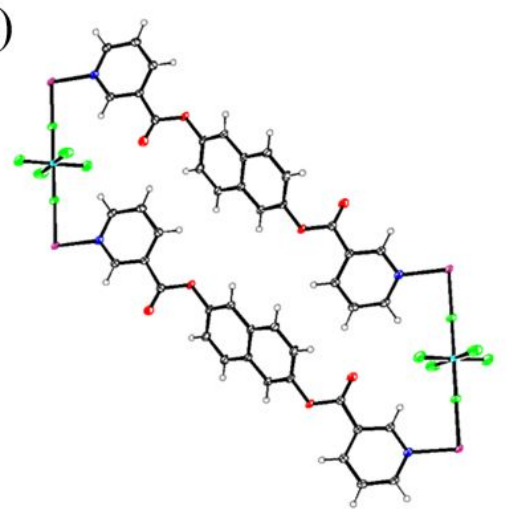

Fig. S3. The ortep diagrams of hybrids 1-2; atom colors: $\mathrm{F}=$ green, $\mathrm{Zn}=$ purple, $\mathrm{Si}=$ cyan, $\mathrm{N}=$ blue, $\mathrm{C}=$ gray, $\mathrm{H}=$ white.

(a)

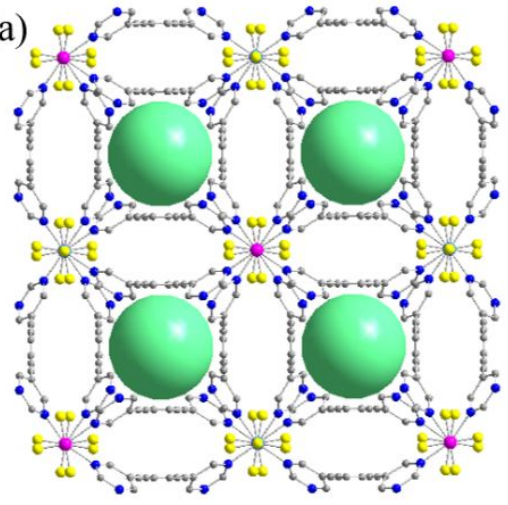

(b)

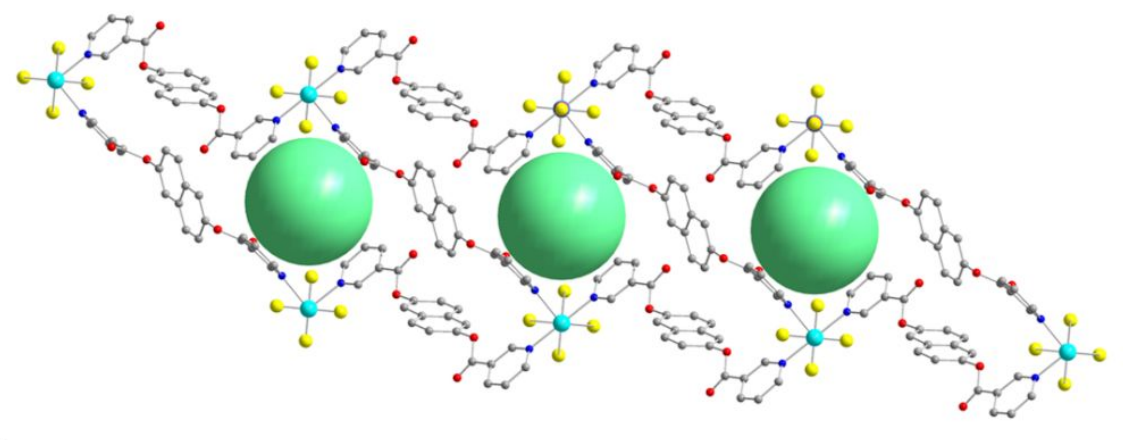

Fig. S4. The the void spaces in hybrids 1-2; atom colors: $\mathrm{F}=$ yellow, $\mathrm{Zn}=$ purple, $\mathrm{Si}=$ cyan, $\mathrm{N}=$ blue, $\mathrm{C}=$ gray. 